\title{
小学语文群文阅读在课堂教学中的应用探析
}

\author{
王书茵 \\ 临沂第二十一中学 \\ DOI:10.32629/er.v3i2.2506
}

[摘 要] 随着经济体制的调整,社会的发展也在稳固的提升,教育事业的改革被提升了到一个新的高度,尤其是在小学教育方面,更加引起了教 育部门的重视。在小学语文教学中,提升孩子们的核心素养逐渐成为了语文教学的重点,越来越先进的教育方法被应用到教学实践中,其中群文 阅读作为一种创造性的语文阅读教学, 较好的弥补了学生在阅读时出现了单一问题, 可以最大化的提升孩子们的学习兴趣, 帮助他们扩展知识面, 让单一的知识变得立体, 发散思维,让学习不再局限于书本上的知识, 多元化的教学更好的提升学生对于各方面知识的认知。本文研究通过对群 文阅读教学和小学语文学科教学的相关文献进行整理分析, 对小学语文群文阅读在课堂教学中存在的问题进行探讨, 发现教学中存在的一些不 足, 针对小学语文群文阅读教学这一难题进行解析, 提出一些针对性的方式方法, 希望可以对小学语文教育提供一定理论支持, 也为广大教育者在 教学方面提供一定的参考。

[关键词] 小学语文; 核心素养; 群文阅读; 课堂教学

\section{1 群文阅读教学的重要性及研究意义}

群文阅读狭义的理解为多文本之意, 群文阅读教学指的是通过阅读教 学手段来提高阅读教学质量的有效方法, 本文提到的群文阅读是指老师选 择一个或者多个议题, 然后围绕这个议题进行阅读和集体构建, 最终达到 一种共识的过程, 笔者探讨的群文阅读是在新课改的背景下, 寻求一种对 学生阅读有益的学习方式, 让学生们能够更有兴趣的参与到语文学习中去, 是一种创造性的新型阅读教学。

阅读是我们从小认知这个世界的重要途径, 它是我们学习知识的基础 方式。在小学教学中, 阅读教学作为语文学科的一个分支, 在整个语文的学 习过程中, 有着重要的作用, 通过阅读学习, 不仅可以培养学生广泛的阅读 兴趣, 扩大知识面, 也可以提升孩子们的人文素养, 性格品味等, 好的阅读 习惯, 对于学生成才是关键的一步。

在新时代的背景下, 社会提倡: “多读书、好读书、读好书、读整本书”。 在小学生教学的过程中, 若只注重书本上的知识, 没有课外的延伸, 那么将 达不到新课标对学生阅读量提出的要求。群文阅读是指老师在课堂上提出 一个或者多个议题, 然后师生围绕这个议题进行阅读与集体构建, 最终达 到共识的过程。在小学的语文教学中, 群文阅读是一种新型的阅读形态, 是对阅读教学一种新的尝试, 对学生更加广泛的学习知识有很大帮助, 培 养孩子思维能力的同时, 更有利于学生核心素养的形成。

\section{2 小学语文群文阅读的现状分析}

当下社会已经成为迅猛发展的信息流社会, 获取知识的方式层出不穷, 以往传统的阅读模式很难满足如今获取知识与信息的需求, 为了在有限的 时间里捕获更多的信息, 提高阅读效率, 扩展知识面是最便捷、最有效的方 式, 在小学语文教学中也显得尤为重要。群文阅读弥补了单篇阅读有限的 问题, 培养阅读兴趣, 提高学生的阅读效率, 是促进学生思维能力培养, 获 取信息的最佳方式, 也是时代发展的迫切需求。

对于小学语文群文阅读的发展情况, 教育研究者根据不同的角度也提 出了一些自己的看法, 如廖椿彪认为群文阅读可以通过确定议题、重组课 文、探究阅读的教学策略来探讨小学语文群文阅读效率最大化的问题; 丁 艳秋指出在小学语文群文阅读教学中可以根据主体选择合适的文章去阅 读, 合理的安排让读者与求知的问题巧妙的结合, 让学生通过阅读对生活 有着更深的感受。

仔细分析教育者提出的有关群文阅读的教学策略, 可以从中发现他们 用着不同的教学策略, 虽然方式不同, 但追求的结果都大同小异, 都比较注
重议题的选择、文本的组合以及最终的集体构建, 这对本文对小学语文群 文阅读在课堂中的应用有一定的参考价值。

\section{3 小学语文群文阅读在课堂教学中的应用}

在小学语文群文阅读的教学过程中, 主要从教师、学生、课堂三个方 面入手。对老师而言, 群文阅读的授课方式改变了以往阅读观念, 通过有计 划的实施, 有助于提升小学语文老师对群文阅读教学的认识, 对于阅读授 课有一些新的启发, 在探索中让老师创造性的展开群文阅读的教学模式, 推动群文阅读教学在课堂中的实施, 实施过程中也让老师获取到更多的信 息与知识, 对于学生来说更是一笔巨大的财富。对学生而言, 在课堂中群文 阅读能够提高学生的阅读速度, 提升学生的阅读量, 在脑中储存更多的知 识与信息, 学生的思维能力以及创造能力都会有一定的提升, 进而培养小 学生语文学科核心素养。对于课堂教学而言, 群文阅读授课方式改变了以 往的教学模式, 转变了课堂中单一书本的状况, 课程的有效实施, 可以收集 到更多的教学素材, 在授课中提高学习效率, 也让学到的知识有一定的深 度与广度, 给学生了提供了更多的想象空间, 对于思维方式的培养有着不 可忽视的作用。

在我国教育体制改革的背景下, 虽然部分小学的教师已经开始在课堂 中尝试开展群文阅读教学, 但是在授课的过程中仍然存在着一定的不足, 如认知不足、授课思路不清晰、教学设计不达标等问题, 这些问题的出现 都会直接的影响到小学语文群文阅读在课堂中的实施, 针对这一系列问题, 笔者提出了一些针对性的意见与看法, 希望对群文阅读授课的顺利进行有 所帮助。

在群文阅读课堂授课的过程中, 需要把握五个关键行为: 比、对、读、 议、整。这五个行为在整个授课中具有重要的作用。“比” 是指授课中用 到的文本语言以及形式对比, 把所需要的信息进行䇻选整理, 辨识, “对” 则是将之前提到的议题进行认识、辨析, 与文本中对应的语言文字相对照, 从中获得追求的阅读体验; “读” 是指我们平常的看书、阅读, 根据文本内 在的含义有意识的选用阅读方法, 来实现信息的获取; “议” 所指在 “比对 读” 的基础上对议题中的人、事、物进行主观的评价与测评, 通过老师、 学生的见解来达成一种对议题的深度理解, 过程中尊重同学的个体差异, 对得出的结果公平对待; “整”即为一种对议题的整合, 通过对议题的理解, 在老师带领下把得到的信息进行整理、归纳, 排除一些错误的观点, 把扩展 开的知识进行吸收, 最大化的提升孩子们的学习阅读能力, 也有效的提升 了学生们的学科核心素养。 
经过小学语文群文阅读的教学, 可以让学生的语文学科核心素养得到 明显的提升, 在阅读能力方面、语言组织能力方面、思维能力方面、审美 与创造力方面等都有一定的帮助, 通过课堂教学可以让学生积累丰富的生 活经验, 也会日后学习其他学科提供支持, 对孩子未来的发展也起到了一 定的引领作用。

\section{4 小学语文群文阅读的教学策略分析}

笔者根据当下小学语文群文阅读的教学现状, 融合语文学科核心素 养的相关理念, 分别对议题设置、文本组合、集体构建三个方面来进行 深入分析, 提炼出小学语文学科课堂教学的相关策略, 为老师在群文阅 读教学中能够更好的完成教学目标提供一定的参考, 希望达成一种愉悦 的授课氛围, 并让学生能够吸收更多的知识, 在学习的广度上能够有一 定的提升。

4. 1教学议题需要紧扣核心素养, 明确教学目标

在小学语文群文阅读的教学中, 选择有价值的议题是群文阅读的关键 所在。在阅读教学过程中, 选取没有意义的议题, 会让学生们在学习时步入 一个错误的导向, 不正确的学习会适得其反, 无法提升孩子的学习能力, 反 而会让他们在学习中更加散漫, 无法完成正常教学。

在议题的选择时要注重学生核心素养的教学, 明确学生在课堂教学 时要达成的教学目标, 有计划、有针对性的完成教学任务, 达成课标的学 科核心素养主要包括：语言的构建与应用、思维方式的发展、审美创造 力的提升、文化的传承与理解四个方面, 因此教师在选择议题的时候, 一 定要关注到语文学科的主要方向, 紧扣核心素养, 让学生们能够沿着正 确的方向学习。

4. 2 文本的组合需要多元化, 选文内容有所关联

在群文阅读的教学过程中, 文本的选取也是很重要的一关, 选文的优 劣在一定程度上决定了教学质量的好坏, 因此在围绕议题选取文本的时候 要格外的重视, 注重选文的内在关联与规律, 让学生能够感受到学习乐趣 的同时, 也能提高阅读效率, 学到更多的知识, 在语言组织能力上、思维方 式上、审美鉴赏能力上都有一定的提升。

在文本选择时需要多元化的选取, 文本的题材要尽可能的丰富, 如电 影、纪录片等, 也可以涉及到小说、散文、童话、寓言、传记等, 多元化非 连续性的文本比较适合小学生的阅读, 在阅读的过程中进行练习比较, 感
受信息的多元化, 提高阅读量的同时, 也能增长更多的见识, 提升语文学科 的核心素养。

4. 3集体构建学生语文素养, 鼓励合作学习

在群文阅读的学习中, 强调解放思想, 提倡一种集体构建知识的学习 方式, 注重集体学习, 改变以往老师单一授课的模式, 让老师与学生之间进 行互动, 以学生为主体, 老师在授课中起到一定的引领作用。在集体构建的 过程中, 学生之间可以聆听到其他人的描述, 对别人的意见进行获取、认 同、接纳, 以教师与学生的不同意见为基础, 最终达成共识为目标。

在集体构建过程中, 通过老师与学生之间的良好配合, 挖掘出学生的 内心所想, 解放思维, 把自己的想法尽情的表达出来, 正确观念加以褒扬, 错误的方向把控纠正, 在授课的过程中, 让学生的语言表达能力与思维方 式都能得到很好的锻炼, 逐步提高学生的语文学科核心素养, 促进学生语 言、思维方式、审美创造力的全面发展。

\section{5 结语}

当下随着信息化时代的发展, 快速获取信息是这个时代的发展要求, 群文阅读在小学生语文的课堂教学的应用, 有效的改善了学生单一阅读的 习惯, 培养了学生的思维方式, 对于提升学生语文核心素养有着特有的价 值。笔者期望群文阅读能够在小学中很好的应用, 这对于老师与学生之间 都是一笔宝贵的财富, 同时也相信各位优秀教育人员能够积极的实践和探 究, 让群文阅读发挥其特有的价值, 促进学生核心素养的全面发展。

\section{[参考文献]}

[1]蒋军晶.让学生学会阅读:群文阅读这样做[M].北京:中国人民大学 出版社,2016:11-12.

[2]于泽元,王雁玲,石潇.群文阅读的理论与实践[M].重庆:西南师范大 学出版社,2018:183-195.

[3]李瑶.小学语文群文阅读教学实践反思[D].四川师范大学,2017.

[4]陈雪晴.基于语文学科核心素养的小学语文群文阅读教学实践研 究[D].重庆师范大学,2019.

作者简介:

王书茵(1988--), 女, 汉族, 吉林省大安人, 小学语文教师, 二级教师, 大学本科,研究方向：小学语文教育。 